\title{
Applications of Bioadhesives: A Mini Review
}

\author{
Wanglin Duan ${ }^{1 \dagger}$, Xiangbing $\mathrm{Bian}^{2 \dagger}$ and Yazhong $\mathrm{Bu}^{1 \text { * }}$ \\ ${ }^{1}$ Department of Biophysics, School of Basic Medical Sciences, Health Science Center, Institute of Medical Engineering, Xi'an \\ Jiaotong University, Xi'an, China, ${ }^{2}$ The First Medical Center of Chinese PLA General Hospital, Beijing, China
}

Bioadhesives have demonstrated their superiority in clinical applications as tissue adhesives, hemostats, and tissue sealants. Because of the intrinsic stickiness, the applications have been expanded to various areas, such as functional wound dressing, factor delivery vehicles, and even medical device fixation. While many literature works discussed the mechanism of bioadhesives, few of them specifically summarized the applications of bioadhesives. To fill in the blanks, this review covers recent research articles and focuses precisely on the applications of bioadhesives which can be generally classified as follows: 1) wound closure, 2) sealing leakage, and 3)

OPEN ACCESS

Edited by:

Francesco Baino,

Politecnico di Torino, Italy

Reviewed by:

Kyung Min Park,

Incheon National University,

South Korea

Ashley Carson Brown, North Carolina State University,

United States

*Correspondence:

Yazhong Bu

yazhongbu@xjtu.edu.cn

${ }^{t}$ These authors have contributed equally to this work

Specialty section:

This article was submitted to Biomaterials,

a section of the journal Frontiers in Bioengineering and Biotechnology

Received: 28 May 2021

Accepted: 22 July 2021 Published: 03 September 2021

Citation:

Duan W, Bian X and Bu Y (2021) Applications of Bioadhesives: $A$

Mini Review.

Front. Bioeng. Biotechnol. 9:716035.

doi: 10.3389/fbioe.2021.716035 immobilization, including those already in the clinic and those showing great potential in the clinic. It is expected that this article will provide a whole picture on bioadhesives' applications and lead to innovations in the application of bioadhesives in new fields.

Keywords: bioadhesive, sealant, wound closure, functional wound dressing, medical device fixation

\section{INTRODUCTION}

Bioadhesives have been changing the surgical process with increasing importance and rapid development over the past 30 years (Ge and Chen, 2020; Taboada et al., 2020). The growing interest in producing adhesives and sealants makes them constitute a market share of $\$ 38$ billion currently (Spotnitz and Burks, 2012; Qu et al., 2018; Liang et al., 2019). Compared with traditional invasive wound closure methods, including sutures, wires, and staples, bioadhesives have less possibility to damage the tissues and can promote wound healing through different mechanisms. For example, the bioadhesives possess antibacterial, anti-inflammatory, and antioxidant properties (Giano et al., 2014; Zhao et al., 2020). Other properties like self-healing and injectability significantly increase bioadhesives' ease of use (Sun et al., 2020). Preventing leakage is also an essential role of bioadhesives. Leakage happens easily after the surgical process, which is up to $30 \%$ in some challenging situations. The leakage will easily lead to pain, inflammation, infection, and a high mortality rate (Artzi, 2013; Slieker et al., 2013; Pausch et al., 2020). With an aim to prevent those postoperative leakages, different bioadhesives have been developed accordingly. FocalSeal ${ }^{\circledR}$ was developed to avoid air leakage during lung surgery. DuraSeal ${ }^{\circledR}$ was designed for the spine and dura sealing. Coseal ${ }^{\circledR}$ was used as an adjunct of suture to prevent the leakage of blood vessels.

Moreover, they can remain stable on the site of application because of the intrinsic adhesion property. So, another important function of bioadhesives is immobilization. They can immobilize themselves as functional wound dressings to promote wound healing without other fixation methods (Yang et al., 2021). They can also be employed as vehicles to deliver functional items like drugs or cells to realize local delivery (Patel et al., 2014; Hu et al., 2021). With the development of smart biomedical devices, like wearable devices, implantable detectors, or sensors, a question has been raised about how to fix those devices on/in the body through noninvasive methods without damaging 


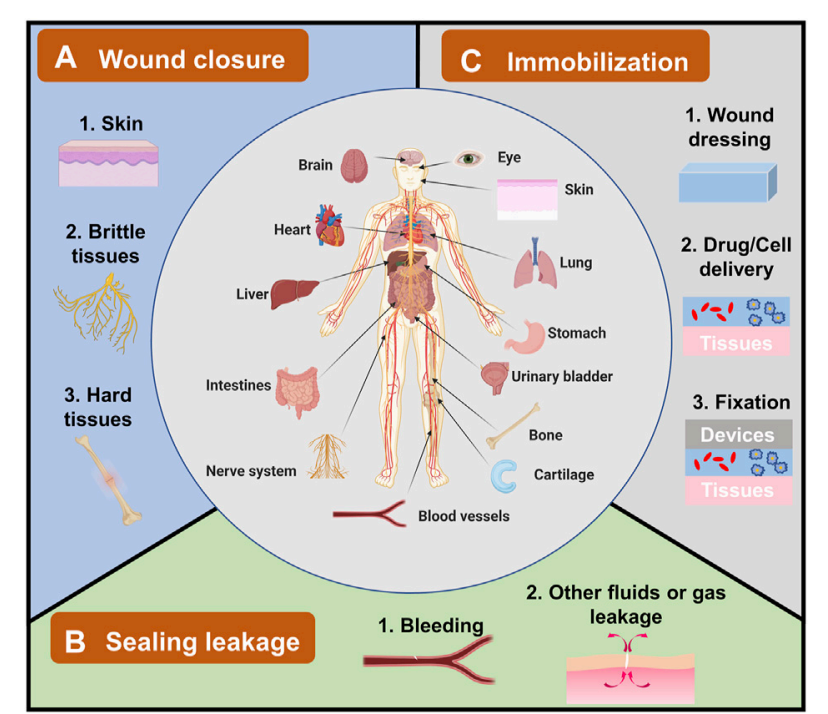

FIGURE 1 | The applications of bioadhesives in human bodies and their categories. Bioadhesives have been explored in human bodies in different organs, including the brain, eyes, heart, liver, and skin. Their applications can be grouped into three categories. (A) Wound closure, which has been used in topical skin, and brittle/hard tissues. (B) Sealing leakage, including most explored blood leakage and other fluids or gas leakage. (C) Immobilization for wound dressing, drug/cell delivery, and fixation of devices.

the tissues or the medical devices, to which the bioadhesive is also a good solution (Hwang et al., 2018; Deng et al., 2021).

Since bioadhesives are being explored in all sorts of fields, there is a need to summarize these applications, including the existing ones and potential ones. However, till now, most reviews focused on either bioadhesives' adhesion mechanism or their applications on wound closure and leakage prevention; they seldom specifically discussed the overall applications of bioadhesives (Zhu et al., 2018; Bao et al., 2020; Ge and Chen, 2020; Taboada et al., 2020). Hence, in this review, the applications of bioadhesives have been summarized and grouped into three categories (Figure 1): 1) wound closure, 2) sealing leakage, and 3) immobilization. The examples of each category were demonstrated with the hope of providing a whole picture of the applications of bioadhesives and accelerating the innovation of bioadhesives in new fields. It is worthy to note that some bioadhesives own properties of two or three categories. Here, the bioadhesives are grouped according to their primary functions and the authors' understanding of the bioadhesives.

\section{WOUND CLOSURE}

Wound closure is one of the most widely used applications of bioadhesives (Table 1). Sutures, wires, and staples have been the routine practice of wound closure for many years (Mehdizadeh and Yang, 2013). However, concerns about the scar tissues, secondary injury, foreign body reaction, wicking-induced infection, impaired wound healing process, and complex postoperative care are still waiting to be addressed (Harsha and Vasudha, 2018). As a good alternative, bioadhesives can adhere two wounds together through a noninvasive behavior. Typically, bioadhesives close the wounds by three methods : bringing the two sides of an injury together from the wound surface (Figure 2A), bringing the tissues beneath the surface together (Figure 2B), or closing wounds in both ways (Figure 2C). Firm adhesion is the property needed for all the three types. Moreover, the bioadhesives applied to wounds (Figures 2A,C) should be biodegradable and biocompatible and should not hinder the healing process (Li et al., 2020). The bioadhesives used on the surface are generally tape-like ones with strong cohesion strength (Bae et al., 2013; Yang et al., 2013). Cohesion, which is defined as the internal strength of an adhesive, together with adhesion creates a strong bond; few people conducted in-depth research on cohesion strength alone. However, it is reported that the photo-crosslinking strategy is commonly used to develop tapelike bioadhesives with high cohesion strength. Besides, the double network strategy has also been used to develop bioadhesive tapes with good wound closure efficacy by increasing the cohesion strength (Liu et al., 2018; Yuk et al., 2019; Pausch et al., 2020). Cyanoacrylate-based bioadhesives are the most widely used tissue adhesives for wound closure in the market, initially synthesized in 1949 (Harsha and Vasudha, 2018). Although they are not tapelike, they play roles mainly according to the second type because of their strong adhesion strength. However, their applications on wet tissues were limited because of their water-initiated curing. They also raise security concerns for exothermic polymerization, cytotoxic degradation products, and long degradation time $\mathrm{Bu}$ et al., 2017; Harsha and Vasudha, 2018). So, special attention should be paid to avoid pushing cyanoacrylate-based bioadhesives into the wound, which can cause irritation and foreign body reaction. There are indications of holding wound edges together for at least $30 \mathrm{~s}$ before releasing. Because of the brittle property of the barriers formed by cyanoacrylate, it is suggested that cyanoacrylates are not suitable for wounds over joints, like the knees, groins, or hands, where adhesion easily fails because of the skin torsion (Harsha and Vasudha., 2018).

\section{Skin Closure}

Skin closure is one of the main goals for wound closure-targeting bioadhesives which is in high demand because of the increasing workload of general surgery (Lu et al., 2020). This application has expanded popularity also because people pay more attention to their physical appearance. Dermal surgeons prefer using bioadhesives to improve their work efficiency. Patients tend to use noninvasive methods because there is usually less pain and a better cosmetic outcome ( $\mathrm{Ge}$ and Chen, 2020). Luo et al. developed a new bioadhesive from the skin secretion of Chinese giant salamander. Later, the ability to close the wound was tested on the back of the rats with four incisions $(2 \mathrm{~cm})$. At the 5th day of postoperation, the bioadhesive-treated group showed the best healing effect among all groups, with no scar formation, infection, and inflammation (Deng et al., 2019). Du et al. fabricated an adhesive patch with poly-(ethylene glycol) diacrylate/quaternized chitosan/tannic acid based on musselinspired chemistry. The efficacy of the wound closure was 
TABLE 1 | Bioadhesives for wound closure.

\begin{tabular}{|c|c|c|c|}
\hline Materials used & Type of the model & Animal species & References \\
\hline \multicolumn{4}{|l|}{ Skin closure } \\
\hline N-acryloyl, 2-glycine (ACG), hydroxyapatite (HAp) & Three incisions $(2 \mathrm{~cm})$ were cut on the back of rats & Male SD rats & Cui et al. (2018) \\
\hline Secretion of Andrias davidianus (SSAD) & Four incisions $(2 \mathrm{~cm})$ were made for each rat & Male SD rats & Deng et al. (2019) \\
\hline Eight-arm poly (ethylene glycol), tannic acid (TA) & $\begin{array}{l}\text { Two incisions }(1.5 \mathrm{~cm}) \text { were made in the separate lateral ribs } \\
\text { at the same distance from the rats' midline }\end{array}$ & Female SD rats & Sun et al. (2020) \\
\hline $\begin{array}{l}\text { Poly (ethylene glycol) diacrylate, quaternized } \\
\text { chitosan, tannic acid }\end{array}$ & $\begin{array}{l}\text { Two full-thickness skin incisions }(2 \mathrm{~cm}) \text { were made on the } \\
\text { rat's back }\end{array}$ & Male BALB/c mice & Du et al. (2019) \\
\hline Chitosan-poly (ethylene glycol)-tyramine (CPT) & $\begin{array}{l}\text { Skin incisions }(1.5 \mathrm{~cm}) \text { were made on both sides of the rat's } \\
\text { back }\end{array}$ & Normal SD rats & Lih et al. (2012) \\
\hline $\begin{array}{l}\text { Deacetylated carboxymethyl chitin, } \mathrm{N} \text {-acetylated } \\
\text { carboxymethyl chitin }\end{array}$ & $\begin{array}{l}\text { A full-thickness incisional wound }(1 \mathrm{~cm}) \text { was created on the } \\
\text { rats }\end{array}$ & Wister rats & Azuma et al. (2015) \\
\hline Citric acid, poly (ethylene glycol), dopamine & $\begin{array}{l}\text { Six full-thickness wounds }(2 \mathrm{~cm} \text { long } \times 0.5 \mathrm{~cm} \text { deep) were } \\
\text { made on the dorsum of each rat }\end{array}$ & Female SD rats & $\begin{array}{l}\text { Mehdizadeh et al. } \\
\text { (2012) }\end{array}$ \\
\hline $\begin{array}{l}\text { Hydrophobic T8 polyhedral oligomeric } \\
\text { silsesquioxane (POSS), trifluoromethanesulfonic acid }\end{array}$ & $\begin{array}{l}\text { Skin incisions ( } 1 \mathrm{~cm} \text { in length and } 1 \mathrm{~cm} \text { in depth) were created } \\
\text { on both sides of the pig's back }\end{array}$ & Bama miniature pigs & Bu et al. (2017) \\
\hline Mussel adhesive proteins (MAPs) & Skin incisions $(2 \mathrm{~cm})$ were made on the skin of the back & Normal SD rats & Jeon et al. (2015) \\
\hline Tannic acid (TA), gelatin methacrylate (GelMA) & $\begin{array}{l}\text { The tension incision model was made by removing a piece of } \\
\text { olivary full-thickness skin around } 1 \mathrm{~cm} \text { in length }\end{array}$ & Athymic mice & Liu et al. (2018) \\
\hline $\begin{array}{l}\text { 4-Arm polyethylene glycol propionaldehyde (PEG- } \\
\text { PALD), chitosan (CS) } \\
\text { Comminuted fracture }\end{array}$ & $\begin{array}{l}\text { Two linear, full-thickness surgical wounds }(1.3 \mathrm{~cm}) \text { were } \\
\text { created on both sides of the spine }\end{array}$ & Balb/c mice & Li et al. (2020) \\
\hline $\begin{array}{l}\text { Citric acid, poly (ethylene glycol), dopamine, } \\
\text { hydroxyapatite }(\mathrm{HA})\end{array}$ & $\begin{array}{l}\text { Osteotomy was performed at two sites with a surgical electric } \\
\text { saw to produce a 10-mm length bone block. The bone blocks } \\
\text { were cut into several segments (usually } 3-4 \text { fragments) using } \\
\text { a bone rongeur }\end{array}$ & Male New Zealand Rabbits & Xie et al. (2015) \\
\hline Chitosan, glycerol, glutaraldehyde & $\begin{array}{l}\text { Bone sheets were cut into rectangular cuboids with a } \\
\text { constant transversal section of } 13 \mathrm{~mm} \times 7.0 \mathrm{~mm} \text {. Along } \\
30 \mathrm{~mm} \text { in the cuboid center, the transversal section was } \\
\text { reduced to } 6.5 \mathrm{~mm} \times 6.5 \mathrm{~mm} \text {. Subsequently, } 4 \text {-mm diameter } \\
\text { holes were drilled at both ends of the cuboid. Finally, the } \\
\text { drilled cuboid was cut in half at the center of its longitudinal } \\
\text { axis with a diamond wheel }\end{array}$ & $\begin{array}{l}\text { Cancellous bones extracted } \\
\text { from bovine humerus head }\end{array}$ & $\begin{array}{l}\text { Cedano Serrano } \\
\text { et al. (2017) }\end{array}$ \\
\hline \multicolumn{4}{|l|}{ Nerve injury closure } \\
\hline $\begin{array}{l}\text { Octa-arm poly (ethylene glycol), octa-arm PEG- } \\
\text { amine, LiCl }\end{array}$ & $\begin{array}{l}\text { The sciatic nerve in the right leg was subjected to a } \\
\text { transection at } 0.5 \mathrm{~cm} \text { distal to the sciatic notch, then octa- } \\
\text { PEG-SS and LiCl-octa-PEG-NH2 were injected into the } \\
\text { interface of the proximal stump and distal stump of the } \\
\text { transected nerve }\end{array}$ & SD rats & Bu et al. (2020) \\
\hline \multicolumn{4}{|l|}{ Vascular anastomosis } \\
\hline $\begin{array}{l}\text { Poloxamer, 2-octylcyanoacrylate adhesive } \\
\text { (Syneture) }\end{array}$ & $\begin{array}{l}\text { The left common iliac artery of the rat was divided and ligated } \\
\text { at the bifurcation and anastomosed to the right common iliac } \\
\text { artery in an end-to-side fashion. Then 2-octylcyanoacrylate } \\
\text { was applied in a circumferential manner to complete the } \\
\text { anastomosis }\end{array}$ & Male Fisher rats & Chang et al. (2011) \\
\hline
\end{tabular}

tested on a full-thickness incision model. It was proved that at day 7 postsurgery, the patch-closed skin incisions exhibited more complete epidermis and dermis structures, and higher collagen deposition levels than the untreated tissues (Du et al., 2019).

\section{Wound Closure of Hard or Brittle Tissues}

Other kinds of wound closure, in which bioadhesives show super advantages, are closing wounds of hard and extremely brittle tissues. In hard tissues like bones, bioadhesives provide a quick and straightforward method to fix the broken pieces, especially for small bone fragments (Farrar, 2012). For example, comminuted bone fracture is a severe orthopedic condition. The difficulty in fixation of the small bone pieces often leads to bone reduction, further resulting in bone displacement, bone union deformation, and nonunion. Based on citrate, Xie et al. developed an injectable bioadhesive to fix small bone pieces in comminuted bone fractures (Xie et al., 2015). Hydroxyapatite was added to the system to improve the healing efficacy. It was demonstrated that the bioadhesive increased bone formation with markedly enhanced three-point bending strength compared with the negative control. In extremely brittle or sensitive tissues like nerves, traditional sutures can cause irreversible damage. Besides, skilled surgeons are required for suturing those tissues, which entails prolonged surgical time and surgical skills. In our previous work, the octa-PEG-based bioadhesives have been used to close the nerve transection. After adding lithium chloride, the adhesive-reconnected nerves showed a low level of fibrosis, inflammation, and myoatrophy, as well as robust axonal regeneration and functional recovery $(\mathrm{Bu}$ et al., 2020). Corneal is another brittle tissue in which closure can 


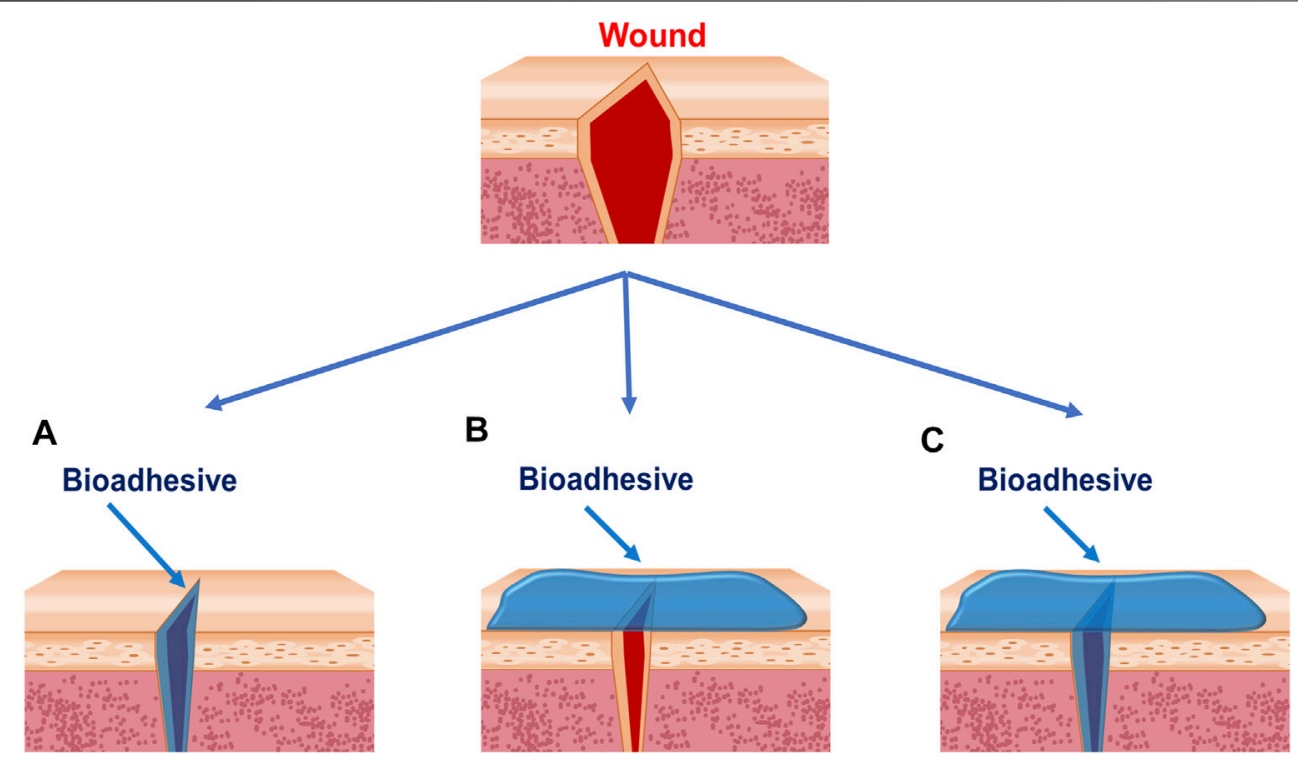

FIGURE 2 | Strategies bioadhesives used to close wounds. (A) Bioadhesives are applied between wound edges. (B) Bioadhesives are applied outside of the wounds. (C) Bioadhesives are applied between and outside the wounds.

be achieved by the bioadhesives. Shirzaei Sani et al. had engineered a gelatin-based adhesive biomaterial GelCORE to close the eye incision in an ex vivo model. It was found that the mean leak pressure of glue was more significant than that of commercial control groups (Shirzaei Sani et al., 2019).

\section{SEALING LEAKAGE}

Leakage is a common complication of surgeries and injuries. After lung resections, the incidence of air leakage was reported to be around 50\% (Mueller and Marzluf, 2014). Cerebrospinal fluid leakage, caused by injuries or brain and sinus surgery, can lead to headaches, meningitis, and seizures. Gastric fluid leakage can cause severe tissue damage and infection, which happens easily after surgical procedures. So leakage prevention is vital in reducing operative risks, and decreasing the complications and the cost. Bioadhesives for leakage prevention are also called tissue sealants, which attracted the attention of researchers and have shown great potential in the clinic (Ryu et al., 2011; Nie et al., 2013; Behrens et al., 2014; Chan Choi et al., 2014; Kim et al., 2015; Chen et al., 2017; Yan et al., 2018; Kim et al., 2020). Some examples of the tissue sealants are summarized in table 2 .

\section{Bleeding}

In this review, bleeding is considered as the leakage of the blood, resulting from trauma, surgical process, diseases, and even some medicines. It is one of the most frequent complications in patients. There are many sealants available in the market for hemostasis, such as Tisseel ${ }^{\circledR}$ (Fibrin sealant), Coseal ${ }^{\circledR}$ (PEG sealant), and Bioglue ${ }^{\circledR}$ (Albumin and Glutaraldehyde). However, they have separate limits. In their indications,
Tisseel ${ }^{\circledR}$ is not suggested for massive bleeding; Coseal ${ }^{\circledR}$ and Bioglue $^{\circledR}$ are suggested to be used as adjunctions to sutures or staples. So, sealants with high efficacy are still highly desired for uncontrollable or massive bleeding. Different strategies have been used to develop bioadhesives for hemostasis. Cui et al. developed a hyperbranched polymer sealant with a hydrophobic backbone and hydrophilic adhesive catechol side. By introducing long alkylamine chain into the structure, their sealant showed efficient hemostasis in the rat's femoral artery bleeding and liver bleeding model (Cui et al., 2019). In our previous work, the concept of fabricating sealants with strong cohesion strength has been used (Bu et al., 2016; Bu et al., 2019). Tough sealants based on ammonolysis-based Tetra-PEG hydrogels were fabricated, which showed promising efficacy in pigskin massive bleeding and rabbit femoral artery section models (Bu et al., 2016). Hemostasis is another critical situation for patients with coagulation disorders, such as hemophilia, Von Willebrand disease, and aged patients taking anticoagulation drugs. Shin et al. presented a hemostatic hypodermic needle that will be able to prevent bleeding following tissue puncture. The surface of the needle was coated with catechol-functionalized chitosan that would be transformed from the solid to the gel phase in situ to seal punctured tissues (Shin et al., 2016). Later, Kim et al. used the catechol-conjugated chitosan to fabricate a hemostatic sponge (Kim et al., 2021). They used preclinical models to evaluate the hemostatic efficacy, including the heparinized rabbit model of femoral artery bleeding, the pig model of traumatic blunt liver injury with hemodilutional and hypothermic coagulopathy, and the anticoagulant-treated rabbit model of liver resection bleeding. A further clinical study performed on 15 patients showed that this sponge demonstrated an excellent hemostatic effect compared with the commercialized controls. 
TABLE 2 | Bioadhesives for sealing leakage.

\section{Materials used}

Hemostasis

Multi-vinyl monomers, dopamine

Multi-vinyl monomers, dopamine

Poly (ethylene glycol), tyramine, chitosan; bovine serum albumin (BSA), Citrate acid, dopamine; chitosan, Pluronic ${ }^{\circledR}$ F127 (PF127-CHO)

Tannic acid, poly (ethylene glycol); chitosan/pluronic composite hydrogel; chitosan/poly-lysine hydrogel;

poly ( $\gamma$-glutamic acid), dopamine hydrochloride (DA);

$\mathrm{N}$-(3-aminopropyl) methacrylamide (APM); DOPA-

modified gelatin; hydrazide-modified poly (L-glutamic acid) (PLGA-ADH), dual-functionalized alginate; epigallocatechin gallates (EGCGs), tyramine,

hyaluronic acids, tyrosinase

DNA from salmon testes, tannic acid

Glycol chitosan (GC), 3-(4-hydroxyphenyl) propionic acid

Tetra-armed poly (ethylene glycol) amine, tetraarmed poly (ethylene glycol) succinimidyl succinate

Tetra-armed poly (ethylene glycol) amine, tetraarmed poly (ethylene glycol) succinimidyl succinate TachoSil (fibrinogen-impregnated sealant), TissuFleece and Tissucol Duo (fibrin glue)

Chitosan

Chitosan

$\mathrm{N}$-(3-aminopropyl) methacrylamide hydrochloride (APM)

Gelatin (Type A), methacrylic anhydride, polyethylene glycol diacrylate (PEGDA-Mn 700)

$\mathrm{N}$-(3-aminopropyl) methacrylamide hydrochloride (APM)

Carboxymethyl chitosan (CMC), gelatin, oxidized alginate (OSA)

Methacrylated gelatin (GelMA), N-(2-aminoethyl)-4(4-(hydroxymethyl)-2-methoxy-5-nitrosophenoxy) butanamide (NB), glycosaminoglycan hyaluronic acid, lithium phenyl-2,4,6-

trimethylbenzoylphosphinate

Methacrylated gelatin (GelMA), N-(2-aminoethyl)-4(4-(hydroxymethyl)-2-methoxy-5-nitrosophenoxy) butanamide (NB), glycosaminoglycan hyaluronic acid, lithium phenyl-2,4,6-

trimethylbenzoylphosphinate

4-Arm poly (ethylene glycol), 4-Arm poly (ethylene glycol) succinimidyl, 4-Arm poly (ethylene glycol) amine, vancomycin

4-Arm poly (ethylene glycol), 4-Arm poly (ethylene glycol) succinimidyl, 4-Arm poly (ethylene glycol)

amine, vancomycin

Chitosan hydrochloride (ChitHCl), dextran dialdehyde (DDA)

Type of the model

Animal species

References

The rat femoral artery was punctured with a 1- Male SD rats $\mathrm{ml}$ syringe needle

One-quarter of the liver lobe was sheared off Liver bleeding was triggered by puncture with a 20-G needle

Liver bleeding was triggered by puncture with an 18-G needle

Liver bleeding was triggered by puncture with a 23-G needle

Liver bleeding was triggered by puncture with a 28-G needle

An incision with a length to be $20 \mathrm{~mm}$ and a depth of $5 \mathrm{~mm}$ was made on the left lobe of the liver

A wound with a diameter of $25 \mathrm{~mm}$ and a depth of $10 \mathrm{~mm}$ was made on the spleen A standardized left hemihepatectomy was performed by resecting the left and medial segment of the liver

The femoral vein was transected

The femoral artery was transected

Tail amputation at 50\% tail length was completed using surgical scissors

Rat tails were marked $4 \mathrm{~cm}$ from the tip and transected with a scalpel

An incision of $5 \mathrm{~cm}$ in length and $1 \mathrm{~cm}$ in depth was made with a surgical scalpel on the right lobe of the sheep's liver

A wound about $1 \mathrm{~cm}$ in length and $2 \mathrm{~mm}$ in depth was made in one lobe of the liver

A 6-mm inner diameter needle was used to pierce the ventriculus sinister of pig hearts; an incision (4-5 mm) was created by needle puncture in the femoral artery

A large $(3 \mathrm{~cm})$ incision was made in the liver; an incision ( $2 \mathrm{~mm}$ ) was created in the femoral artery

An incision of $1 \mathrm{~cm}$ in length and $0.5 \mathrm{~cm}$ in depth was made in the liver

Femoral artery transection

Liver lobe edge resection of approximately $1.5 \mathrm{~cm}$ length at two sites; liver lobe circular excision of approximately $1 \mathrm{~cm}$ diameter at one site
Male SD rats

SD rats; C57BL/6 mice; Kunming mice

Normal ICR mice; SD rats; Female balb-c mouse

CR mice

Male BALB/c mice

New Zealand white rabbits

Bama miniature pigs

Landrace pigs

Male Long-Evans rats Yorkshire crossbred swine,

SD rats

Male Wistar rats

Adult Dorsett hybrid sheep

Normal SD rats

Male Bama Miniature pigs

Male New Zealand white rabbits

New Zealand white rabbits

New Zealand white rabbits

New Zealand white rabbits
Cui et al. (2019)

Cui et al. (2019)

(Lih et al. 2012, Zhu et al. 2017, and Qu et al. 2018)

(Ryu et al. 2011, Nie et al. 2013, Behrens et al. 2014, Chan Choi et al. 2014, Kim et al. 2015, Chen et al. 2017, Yan et al. 2018, and Kim et al. 2020)

Shin et al. (2015)

Lu et al. (2018)

Bu et al. (2019)

Bu et al. (2019)

Fonouni et al. (2017)

Dowling et al. (2011)

Dowling et al. (2011)

Behrens et al. (2014)

Krishnadoss et al. (2019)

Behrens et al. (2014)

Cao et al. (2019)

Hong et al. (2019)

Hong et al. (2019)

Bu et al. (2016)

Bu et al. (2016)

Balakrishnan et al. (2017)

(Continued on following page) 
TABLE 2 | (Continued) Bioadhesives for sealing leakage.

\begin{tabular}{|c|c|c|c|}
\hline Materials used & Type of the model & Animal species & References \\
\hline Dextran sodium periodate & $\begin{array}{l}\text { An incision of } \sim 1 \mathrm{~cm} \text { in length and } \sim 0.2 \mathrm{~cm} \text { in } \\
\text { depth was fabricated with a surgical scalpel } \\
\text { on the ear-vein of the rabbit; the uncontrolled } \\
\text { hemorrhage model was created by cutting a } \\
\text { wound on the rabbit's femoral artery by using } \\
\text { ophthalmic scissors }\end{array}$ & $\begin{array}{l}\text { Male New Zealand } \\
\text { white rabbits }\end{array}$ & Liu et al. (2019) \\
\hline 4-Arm-poly (ethylene glycol) succinimidyl, Lysozyme & $\begin{array}{l}\text { The iatrogenic injury of the blood vessel was } \\
\text { created by a } 0.5 \times 20-\mathrm{mm} \text { medical needle }\end{array}$ & Rabbits & Tan et al. (2019) \\
\hline $\begin{array}{l}\text { Glycerol, sebacic acid } \\
\text { Other leakage prevention }\end{array}$ & Carotid artery defects model & Yorkshire pigs & Lang et al. (2014) \\
\hline $\begin{array}{l}\text { Bovine serum albumin (BSA), citrate acid, dopamine; } \\
\text { gelatin, dopamine, genipin }\end{array}$ & Rat mastectomy model & Female SD rats & $\begin{array}{l}\text { (Zhu et al., } 2017 \text { and Yanagihara et al. } \\
\text { 2021) }\end{array}$ \\
\hline $\begin{array}{l}\text { Gelatin type A, methacrylic anhydride (MA), tannic } \\
\text { acid (TA) }\end{array}$ & $\begin{array}{l}\text { An incision }(\sim 1 \mathrm{~cm}) \text { was made on the mouse's } \\
\text { stomach }\end{array}$ & C57BL/6J mice & Liu et al. (2018) \\
\hline $\begin{array}{l}\text { Polydextran aldehyde (PDA), branched } \\
\text { polyethylenimine (PEI) }\end{array}$ & Cecal ligation and puncture model & C57BL/6 mice & Giano et al. (2014) \\
\hline $\begin{array}{l}\text { Poly (lactic-co-glycolic acid) (PLGA), poly (ethylene } \\
\text { glycol) }\end{array}$ & Cecal intestinal anastomosis survival model & C57BL6/J mice & Behrens et al. (2015) \\
\hline Methacryloyl-substituted tropoelastin (MeTro) & $\begin{array}{l}\text { Standard incision }(15 \mathrm{~mm} \times 15 \mathrm{~mm} \times 1 \mathrm{~mm} \text { ) } \\
\text { was generated on the lung with a scalpel }\end{array}$ & Yorkshire pigs & Annabi et al. (2017) \\
\hline Gelatin & $\begin{array}{l}\text { Pleural defects in ex vivo and in vivo porcine } \\
\text { models }\end{array}$ & Pigs & Elvin et al. (2010) \\
\hline Methacrylated gelatin (GelMA) & $\begin{array}{l}\text { A standardized lung lobe incision ( } 3 \mathrm{~mm} \text { in } \\
\text { length; } 5 \mathrm{~mm} \text { in depth toward the hilum) was } \\
\text { generated }\end{array}$ & Male Wistar rats & Assmann et al. (2017) \\
\hline Methacrylated gelatin (GelMA) & $\begin{array}{l}\text { Standardized visceral pleural defect (15 mm } \\
\text { in length; } 15 \mathrm{~mm} \text { in width; } 1 \mathrm{~mm} \text { in depth) was } \\
\text { generated }\end{array}$ & Pigs & Assmann et al. (2017) \\
\hline Gelatin, dopamine-conjugate gelatin (GelDA) & $\begin{array}{l}\text { A small }(3 \mathrm{~mm}) \text { incision was created in the } \\
\text { murine small bowel; a surgical incision } \\
(2-4 \mathrm{~mm}) \text { was made in one of the uterine } \\
\text { horns }\end{array}$ & C57/BL6 mice & Hong et al. (2016) \\
\hline $\begin{array}{l}\text { Polyvinyl alcohol (PVA), poly (acrylic acid) (PAA), } \\
\text { N-hydroxysuccinimide (NHS) ester, sodium } \\
\text { bicarbonate (SBC), glutathione }\end{array}$ & $\begin{array}{l}\text { A laceration was made on a porcine lung lobe } \\
\text { with a razor blade ( } 3 \mathrm{~cm} \text { in length); the air was } \\
\text { applied through the tubing connected to the } \\
\text { upper part of the trachea ( } 25-\mathrm{mmHg} \\
\text { pressure) to visualize air leakage with or } \\
\text { without bioadhesive }\end{array}$ & Pig & Chen et al. (2020) \\
\hline
\end{tabular}

\section{Other Leakages}

Except for blood leakage, there are also some other leakage types. In lung surgery, prolonged air leakage is the most common complication after surgical dissection and resection. The criteria of an ideal sealant for lung leakage include the following: 1 . The sealant can stand higher burst pressure than that generated during physiological breathing; 2 . the sealant should be elastic with a proper elastic modulus to support the inflation and deflation of lung tissue. Annabi et al. used methacryloyl-substituted tropoelastin (MeTro) to engineer a highly flexible sealant (Assmann et al., 2017). After applying MeTro to a porcine model, it was found that the sealant completely sealed the severely leaking lung tissue in the absence of sutures or staples. Urinary fistulas have been considered a severe socioeconomic problem, which occurs most commonly as a result of prolonged obstructed labor, which causes pelvic floor ischemia and, at times, substantial tissue loss (Margules and Rovner, 2019). Kim et al. developed water-immiscible mussel protein-based bioadhesive, which successfully sealed ex vivo urinary fistulas and provided good durability and high compliance (Kim et al., 2015). Liu et al. developed gelatin methacrylate-based double-network hydrogel to manage the leakage of gastric contents without sutures successfully (Liu et al., 2018).

\section{IMMOBILIZATION}

The last category for bioadhesives includes those for immobilization (Table 3). Because of the intrinsic adhesion property, they can immobilize themselves as functional wound dressing or delivery vehicles. By adhering items together, they even can fix other medical devices.

\section{Functional Wound Dressings}

Advanced fixation methods are still in need because traditional wound dressing methods lack the ability of adhesion to wounds, which increases the operative difficulty index for both the patients and doctors. Compared with these methods, bioadhesives can easily fix themselves on the wound area, contributing to the increasing popularity of bioadhesives to be used as a functional wound dressing (Liang et al., 2019; Zhao et al., 2017; Blacklow et al., 2019; Han et al., 
TABLE 3 | Bioadhesives for immobilization.

Materials used

Type of the mode

About $1 \mathrm{~cm}$ diameter full-thickness round skin wounds were created by a needle biopsy $7 \mathrm{~mm}$ diameter full-thickness round skin wounds were created by a needle biopsy

$7 \mathrm{~mm}$ diameter full-thickness round skin wounds were created by a needle biopsy

A full-thickness dorsal excisional skin wound was created on the mice with a sterile 8-mm-diameter biopsy punch following the removal of hair A disposable biopsy punch was used to create a full-thickness round skin wound (diameter = $10 \mathrm{~mm}$ ) on the back

Polydopamine-clay-polyacrylamide (PDA-clay-PAM) hydrogel

Polydopamine-polyacrylamide (PDA-PAM) hydrogel

Ag-Lignin NPs-PAA-pectin hydrogel

Functional wound dressings-corneal defects Gelatin, methacrylic anhydride (MA)

Functional wound dressings-cartilage defects Polydopamine-chondroitin sulfate-polyacrylamide (PDA-CS-PAM) hydrogel

Functional wound dressings-calvarial defects Acrylate b-cyclodextrin (Ac-b-CD), methacrylated gelatin (MeGel)

Functional wound dressings-myocardial infarction (MI) Gelatin methacryloyl (GelMA), choline-based bio-ionic liquid (Bio-IL)

Waxy starch

Drug/Cell delivery

Methacrylated alginate (Alg-DA-MA), Gingival mesenchymal stem cells (GMSCs), HAp microparticles (MPs)

Poly (ethylene glycol), catechol

HA-catechol (HA-CA) hydrogel
Full-thickness skin wounds were created on the dorsal area of the rats

Four full-thickness circular wounds $(5 \mathrm{~mm}$ in diameter) were created on the upper back of each mouse by a disposable $5 \mathrm{~mm}$ skin biopsy punch Four full-thickness circular wounds $(8 \mathrm{~mm}$ in diameter) were created on the upper back of the rats

A 3-mm biopsy punch was used to make a partial trephination (cut) in the central cornea of the right eye to a depth of approximately $50 \%$

A full-thickness defect (diameter: $3.5 \mathrm{~mm}$; thickness: $5 \mathrm{~mm}$ ) was created through the articular cartilage and subchondral bone of the patellar groove in the right leg of the rabbits using an electric drill

Two 5-mm-diameter craniotomy defects were created in the parietal bones of the skull on each side of the sagittal suture line

Immediately after the induction of Ml, the scaffolds were delivered to the surface of the left ventricle, distal to the site of Ml, and photo-crosslinked for 3000 s using UV light

The materials were patched onto the $\mathrm{Ml}$ site of the heart.

Ex vivo-expanded human GMSC aggregates/HAp MPs $(4 \times 106)$ were encapsulated in adhesive hydrogel and implanted subcutaneously $(0.50 \mathrm{ml})$ into the dorsal surface of a 5-month-old Beige nude XID III (nu/nu) (Harlan, United States) mice; titanium implants (ACE Surgical Supply, Brockton, MA) were used to introduce a well-characterized strain of $A$. actinomycetemcomitans biofilm transmucosally into rats

Islet transplantation: approximately $100 \mathrm{ml}$ cPEG was applied following islet deposition directly on this tissue surface

Hepatocyte transplantation: hepatocytes encapsulated in HA-CA hydrogel were transplanted onto the lobe of the native liver or liver with partial hepatectomy of athymic mice using a pipette; HA-CA hydrogel was painted onto the infarction site immediately after induction of hydrogel crosslinking

References

Female Kunming mice

Female Kunming mice

Female Kunming mice

Female C57BL/6J mice

Streptozotocin-induced diabetic SD rat

Male SD rats

Male SD rats

Male SD rats

Male New Zealand white rabbits

Japanese white rabbits

Han et al. (2018)

Male SD rats

Feng et al. (2016)

Balb/C mice

Walker et al. (2019)

SD rats

Lin et al. (2019)

Beige nude XID III (nu/nu) (Harlan, United States) mice; Male and female SD rats

Hasani-Sadrabadi et al. (2020)

Streptozotocin-induced diabetic mice

Female athymic mice (Balb/cnu); Male Hsd $\mathrm{RH}$-rnu rats with myocardial infarction
Brubaker et al. (2010)

Shin et al. (2015) 
TABLE 3 | (Continued) Bioadhesives for immobilization.

\begin{tabular}{|c|c|c|c|}
\hline Materials used & Type of the model & Animal species & References \\
\hline Tetra-PEG/agar hydrogel (PA) & $\begin{array}{l}\text { The drug containing hydrogel was formed in situ on } \\
\text { the surface of the rats' skin }\end{array}$ & $\mathrm{SD}$ rats & Zhang et al. (2019) \\
\hline Tannic acid, poly (ethylene glycol) & $\begin{array}{l}\text { Each mouse was fed on } 0.02 \text { cc of the ICG- } \\
\text { encapsulated TAPE-OH for the adhesion to the } \\
\text { esophagus without any anesthesia }\end{array}$ & BALBc nude mice & $\begin{array}{l}\text { (Kim et al., 2015; Shin } \\
\text { et al., 2016) }\end{array}$ \\
\hline $\begin{array}{l}\text { Wheat germ agglutinin (WGA)-conjugated liposomes } \\
\text { (WGA-liposomes) }\end{array}$ & $\begin{array}{l}\text { The OKF6/TERT-2 cell suspension ( } 1 \times 104 \text { cells) } \\
\text { was seeded onto poly-d-lysine coated glass } \\
\text { bottom micro-well dishes (MatTek Corporation) } \\
\text { and allowed to grow in cell culture media for } 24 \mathrm{~h} \text {. } \\
\text { WGA-conjugated CFPE liposomes (WGA-CFPE- } \\
\text { liposomes) were added to the micro-well dishes } \\
\left(45 \mathrm{\mu g} / \mathrm{ml} \text { lipid) and incubated at } 37{ }^{\circ} \mathrm{C} \text { for } 2 \mathrm{~h}\right.\end{array}$ & OKF6/TERT-2 cell & Wijetunge et al. (2018) \\
\hline $\begin{array}{l}\text { GO (graphene oxide) hybrid supramolecular hydrogels } \\
\text { (GO-HSH) }\end{array}$ & $\begin{array}{l}\text { DOX-loaded GO-HSH hydrogel coating on } \\
\text { titanium substrate and drug release to kill Hela }\end{array}$ & Hela & Chen et al. (2018) \\
\hline $\begin{array}{l}\text { Poly (lactic acid)-hyperbranched polyglycerol (PLA- } \\
\text { HPG), camptothecin (CPT) }\end{array}$ & $\begin{array}{l}\text { PDVC57 cells were harvested, washed, and } \\
\text { resuspended, then injected into the dorsal right } \\
\text { flank. Tumors were injected with BNP-CPT and } \\
\text { visualized particle distribution via confocal } \\
\text { microscope } 72 \text { h after injection }\end{array}$ & Wild-type C57BL/6J mice & Hu et al. (2021) \\
\hline \multicolumn{4}{|l|}{ Medical device fixation } \\
\hline $\begin{array}{l}\text { GO (graphene oxide)-PVA (poly (vinyl alcohol)) } \\
\text { hydrogel, GO (graphene oxide)-PVA (poly (vinyl alcohol) } \\
\text { PAA (poly (acrylic acid)) -NHS(N-hydroxysuccinimide) } \\
\text { ester hydrogel }\end{array}$ & $\begin{array}{l}\text { The heart was exposed via a thoratomy, } \\
\text { bioadhesive electrodes were used to record } \\
\text { epicardial ECG. } \\
\text { A circuit with light emitting diodes (LEDs) was } \\
\text { applied to the ex vivo porcine heart (by introducing } \\
\text { cyclical, pressurized air inputs into the heart } \\
\text { chambers to mimic heartbeats) to test if electrical } \\
\text { communication was stable enough. }\end{array}$ & $\begin{array}{l}\text { Female Sprague-Dawley rats. } \\
\text { Ex vivo porcine heart }\end{array}$ & Deng et al. (2021) \\
\hline
\end{tabular}

2017; Han et al., 2017; Gan et al., 2019). They are favorite candidates for skin damage, one of the most common physical injuries in human history. Based on quaternized chitosan (QCS) and benzaldehydeterminated Pluronic ${ }^{\circledR}$ F127, Qu et al. developed antibacterial bioadhesives with rapid self-healing, extensibility, and compressibility for joints and skin wound healing ( $\mathrm{Qu}$ et al., 2018). They loaded curcumin into the bioadhesive and found that it significantly accelerated wound healing with a higher granulation tissue thickness in a full-thickness skin defect model. Inspired by embryonic wound closure, Blacklow et al. fabricated mechanically active dressings to accelerate wound healing (Blacklow et al., 2019). The bioadhesive dressing will contract at body temperature, which further applies force to draw the wound edges together in a pursestring-like manner. Adhesive dressings are beneficial in places where the fixation is difficult, like brittle tissues. Lin et al. developed a viscoelastic adhesive patch that accommodates the cyclic deformation of the myocardium. It was found that the patch outperformed most existing acellular epicardial patches in reversing left ventricular remodeling and restoring heart function after both acute and subacute myocardial infarctions in rats (Lin et al., 2019). In addition to the heart, defects from the corneal, cartilage, and calvarial were explored to be treated with bioadhesives with good outcomes (Feng et al., 2016; Han et al., 2018; Lin et al., 2019; Shirzaei Sani et al., 2019).

\section{Delivery Systems}

Compared with the traditional hydrogel delivery system, the advantage of bioadhesives in delivery is that they can fix delivered items on the site. Mucoadhesion is very useful in increasing the bioavailability of poorly absorbed drugs by prolonging the residence time in the gastrointestinal tract, leading to reduced dose and dosing frequency (Han et al., 2012; Gong et al., 2017). A lot of mucoadhesive-based delivery systems were developed with some well-summarized reviews (Reddy et al., 2011; Zhang et al., 2016; Zhang et al., 2020; Pathak and Malviya, 2020). $\mathrm{Hu}$ et al. encapsulated camptothecin into poly(lactic acid)-hyperbranched polyglycerol-based nano-bioadhesive particles (NPs). Because of the strong bonding of these NPs to squamous cell carcinoma tumor cells, the system significantly reduced the tumor burden and enhanced survival (Hu et al., 2021). Except for the nano/micro scale mucoadhesion, macro-bioadhesives have also been developed to load drugs to achieve better healing efficacy (Zhang et al., 2019; Bu et al., 2020). Cells can also be loaded into the bioadhesives. The use of an appropriate scaffold biomaterial as a cell delivery vehicle can provide a suitable microenvironment to prolong cell viability and present essential factors to direct cell differentiation toward the desired lineages (Khademhosseini and Langer, 2016). Currently, however, a major drawback of the reported cellladen hydrogels is the weak adhesion to the host tissue at the defective site. Hasani-Sadrabadi et al. used alginate-based photocrosslinkable bioadhesives to load mesenchymal stem cells. It was found that the cell-loaded adhesive system leads to complete bone regeneration around the ailing dental implants with peri-implant bone loss (Hasani-Sadrabadi et al., 2020). 


\section{Fixation of Other Medical Devices}

Nowadays, a growing interest is centered on implantable and wearable medical devices with excellent translational potential in the clinic, like tissue scaffolds, biosensors, and biodetectors. However, it is crucial to establish conformal and stable contact between those devices and the target tissue (Schiavone and Lacour, 2019; Yuk et al., 2019). Wires and sutures are required for this fixation, which raises concerns of infection, secondary tissue injury, and scaffold damage. As a noninvasive adhesion method, bioadhesives have the potential to replace these invasive fixation methods. Based on a thin layer of a graphene nanocomposite, Deng et al. developed an electrical bioadhesive that can provide rapid, robust, and on-demand detachable integration of bioelectronic devices on diverse wet dynamic tissues (Deng et al., 2021). Later, they successfully used the e-bioadhesive to record an in situ epicardial electrocardiogram and electrically stimulated a sciatic nerve on a rat model. This technique offers a promising solution for addressing the long-standing challenges in tissue-device integration. Another good aspect of bioadhesives to be used in these situations is that different functions can be added into the bioadhesives to improve the outcome of the medical devices or reduce the potential complications. For example, the antibacterial property can be introduced to reduce the chance of medical devices' infection (Hwang et al., 2018). In fact, there is still a vast area of bioadhesives in medical device fixation waiting to be explored. However, one should be careful because the bioadhesives may also adversely influence the medical devices. Macnab et al. showed that Tisseel ${ }^{\circledR}$ significantly attenuated NIR light of a near-infrared spectroscopy during in vitro transmittance and critically compromised photo transmission in vivo (Macnab et al., 2018). Another fixation method is also required when there is a need for tissue transplantation. Islet transplantation is used to treat type I diabetes by replacing the lost beta cell function. Brubaker et al. directly immobilized islets onto intra-abdominal tissue surfaces using a thin layer of a mussel-inspired bioadhesive (Brubaker et al., 2010). On the one hand, the fixation approach offers the potential advantages for convenient, rapid, and minimally invasive islet transplantation by direct apposition of the islet bolus onto tissue surfaces. On the other hand, the technique avoids the intravascular engraftment site, eliminating adverse effects of first-pass blood exposure in the liver while maintaining the capability of rapid islet revascularization and the benefits of direct insulin secretion into the portal circulation.

\section{PERSPECTIVE}

Bioadhesives are believed to revolutionize the surgical process (Mehdizadeh and Yang, 2013; Taboada et al., 2020). They have already been widely used as adhesives and sealants in the clinic to reduce complications and improve outcomes. However, those commercialized products are still far from satisfactory. Fibrin-based, PEG-based, and cyanoacrylate-based bioadhesives are the most commonly used ones. Fibrin-based and PEG-based bioadhesives have good biocompatibility but weak adhesion strength. So, most of them are only used as adjunctions for traditional wound closure or sealing methods. Cyanoacrylate-based bioadhesives have strong adhesion strength, but their potential safety concerns limit their wide applications, especially internal applications. Thus, more powerful and commercially transformable bioadhesives for wound closure and sealing leakage are still needed.

Compared with traditional wound dressings, bioadhesives get easily attached to the parts where they are applied because of their intrinsic adhesion property (Li and Mooney., 2016). So, there is a growing interest in using bioadhesives as a functional wound dressing. This application is beneficial for tissues where the fixation of traditional wound dressing fails to work, like a beating heart and brittle brain (Lin et al., 2019). However, the absence of removability makes it hard for further wound care or dressing change, resulting in more potential troubles when mechanical debridement is involved. So controllably removable property is also explored for bioadhesives (Chen et al., 2020; Bu et al., 2019; Villa-Camacho et al., 2015; Konieczynska et al., 2016).

Using bioadhesives for the local delivery of functional items like drugs or cells is also a promising way to realize specialized and prolonged effectiveness. Compared with conventional hydrogel vehicles, bioadhesives can adhere to tissues, making them more stable in special tissues like the beating heart and esophagus (Lin et al., 2019). By mixing Tannic and PEG, Lee et al. developed a new medical glue called TAPE, which had been applied to the esophagus and demonstrated the ability to detect gastroesophageal reflux diseases because it maintained wet-adhesive properties (Kim et al., 2015). Bioadhesives are also used to fix medical devices or tissues, of which the importance is increasing with an increasing number of implantable medical devices and tissue transplantation. The fixation using bioadhesives will not damage either medical devices or the tissues. Although very promising, there is a difficulty in avoiding the interference between the functions of medical devices and bioadhesives. Besides, for tissue transplantation, the adhesion strength of bioadhesives available might not be sufficient for large pieces of tissues.

Although massive efforts have been spent on developing bioadhesives, there are only a handful of products available in the market (Taboada et al., 2020). First, the researcher might care too much about the adhesion mechanism, while cohesion is ignored. Cohesion dramatically influences how the bioadhesives would be used, which is particularly important for clinical translation. In the market, ease of use has a positive influence on people's choices. Second, one bioadhesive never fits all the applications. The requirement of bioadhesives for wound closure differs from those for sealing leakage. So, it is suggested to choose the unmet clinical target first and then the relative characterization methods to fabricate bioadhesives for translation.

\section{AUTHOR CONTRIBUTIONS}

WD did the literature search and paper writing. XB did the literature research and helped revise the paper. YB was responsible for the whole paper design and manuscript organization.

\section{ACKNOWLEDGMENTS}

We sincerely thank Abhay Pandit for offering inspiration and practical advice, as well as writing support for this publication. The study was funded by 'Young Talent Support Plan' of Xi'an Jiaotong University. 


\section{REFERENCES}

Annabi, N., Zhang, Y.-N., Assmann, A., Sani, E. S., Cheng, G., Lassaletta, A. D., et al. (2017). Engineering a Highly Elastic Human Protein-Based Sealant for Surgical Applications. Sci. Transl. Med. 9 (410), eaai7466. doi:10.1126/ scitranslmed.aai7466

Artzi, N. (2013). Sticking with the Pattern for a Safer Glue. Sci. Translational Med. 5 (205), 205ec161. doi:10.1126/scitranslmed.3007663

Assmann, A., Vegh, A., Ghasemi-Rad, M., Bagherifard, S., Cheng, G., Sani, E. S., et al. (2017). A Highly Adhesive and Naturally Derived Sealant. Biomaterials 140, 115-127. doi:10.1016/j.biomaterials.2017.06.004

Azuma, K., Nishihara, M., Shimizu, H., Itoh, Y., Takashima, O., Osaki, T., et al. (2015). Biological Adhesive Based on Carboxymethyl Chitin Derivatives and Chitin Nanofibers. Biomaterials 42, 20-29. doi:10.1016/ j.biomaterials.2014.11.043

Bae, W. G., Kim, D., Kwak, M. K., Ha, L., Kang, S. M., and Suh, K. Y. (2013). Enhanced Skin Adhesive Patch with Modulus-Tunable Composite Micropillars. Adv. Healthc. Mater. 2 (1), 109-113. doi:10.1002/ adhm.201200098

Balakrishnan, B., Soman, D., Payanam, U., Laurent, A., Labarre, D., and Jayakrishnan, A. (2017). A Novel Injectable Tissue Adhesive Based on Oxidized Dextran and Chitosan. Acta Biomater. 53, 343-354. doi:10.1016/ j.actbio.2017.01.065

Bao, Z., Gao, M., Sun, Y., Nian, R., and Xian, M. (2020). The Recent Progress of Tissue Adhesives in Design Strategies, Adhesive Mechanism and Applications. Mater. Sci. Eng. C 111, 110796. doi:10.1016/j.msec.2020.110796

Behrens, A. M., Lee, N. G., Casey, B. J., Srinivasan, P., Sikorski, M. J., Daristotle, J. L., et al. (2015). Biodegradable-Polymer-Blend-Based Surgical Sealant with Body-Temperature-Mediated Adhesion. Adv. Mater. 27 (48), 8056-8061. doi:10.1002/adma.201503691

Behrens, A. M., Sikorski, M. J., Li, T., Wu, Z. J., Griffith, B. P., and Kofinas, P. (2014). Blood-aggregating Hydrogel Particles for Use as a Hemostatic Agent. Acta Biomater. 10 (2), 701-708. doi:10.1016/j.actbio.2013.10.029

Blacklow, S. O., Lisker, S., Ng, M. Y., Sarkar, U., and Lyles, C. (2019). Bioinspired Mechanically Active Adhesive Dressings to Accelerate Wound Closure. Sci. Adv. 5 (7), eaaw3963. doi:10.1126/sciadv.aaw3963

Brubaker, C. E., Kissler, H., Wang, L.-J., Kaufman, D. B., and Messersmith, P. B. (2010). Biological Performance of Mussel-Inspired Adhesive in Extrahepatic Islet Transplantation. Biomaterials 31 (3), 420-427. doi:10.1016/ j.biomaterials.2009.09.062

Bu, Y.-z., Sun, G.-f., Zhang, L.-c., Liu, J.-h., Yang, F., Tang, P.-f., et al. (2017). POSSmodified PEG Adhesives for Wound Closure. Chin J. Polym. Sci. 35 (10), 1231-1242. doi:10.1007/s10118-017-1958-x

Bu, Y., Wang, X., Li, L., Hu, X., Tan, D., Li, Z., et al. (2020). Lithium Loaded OctaPoly(Ethylene Glycol) Based Adhesive Facilitates Axon Regeneration and Reconnection of Transected Peripheral Nerves. Adv. Healthc. Mater. 9 (13), 2000268. doi:10.1002/adhm.202000268

Bu, Y., Zhang, L., Liu, J., Zhang, L., Li, T., Shen, H., et al. (2016). Synthesis and Properties of Hemostatic and Bacteria-Responsive In Situ Hydrogels for Emergency Treatment in Critical Situations. ACS Appl. Mater. Inter. 8 (20), 12674-12683. doi:10.1021/acsami.6b03235

Bu, Y., Zhang, L., Sun, G., Sun, F., Liu, J., Yang, F., et al. (2019). Tetra-PEG Based Hydrogel Sealants for In Vivo Visceral Hemostasis. Adv. Mater. 31 (28), 1901580. doi:10.1002/adma.201901580

Cao, J., Xiao, L., and Shi, X. (2019). Injectable Drug-Loaded Polysaccharide Hybrid Hydrogels for Hemostasis. RSC Adv. 9 (63), 36858-36866. doi:10.1039/ c9ra07116d

Cedano Serrano, F. J., Pinzón, L. M., Narváez, D. M., Castro Paéz, C. I., Moreno-Serrano, C. L., Tabima, D. M., et al. (2017). Evaluation of a WaterResistant and Biocompatible Adhesive with Potential Use in Bone Fractures. J. Adhes. Sci. Technology 31 (13), 1480-1495. doi:10.1080/ 01694243.2016.1263055

Chan Choi, Y., Choi, J. S., Jung, Y. J., and Cho, Y. W. (2014). Human Gelatin Tissue-Adhesive Hydrogels Prepared by Enzyme-Mediated Biosynthesis of DOPA and Fe3+ion Crosslinking. J. Mater. Chem. B 2 (2), 201-209. doi:10.1039/c3tb20696c
Chang, E. I., Galvez, M. G., Glotzbach, J. P., Hamou, C. D., El-ftesi, S., Rappleye, C. T., et al. (2011). Vascular Anastomosis Using Controlled Phase Transitions in Poloxamer Gels. Nat. Med. 17 (9), 1147-1152. doi:10.1038/nm.2424

Chen, W., Wang, R., Xu, T., Ma, X., Yao, Z., Chi, B., et al. (2017). A Mussel-Inspired Poly $\gamma$-Glutamic Acid) Tissue Adhesive with High Wet Strength for Wound Closure. J. Mater. Chem. B 5 (28), 5668-5678. doi:10.1039/c7tb00813a

Chen, X., Yuk, H., Wu, J., Nabzdyk, C. S., and Zhao, X. (2020). Instant Tough Bioadhesive with Triggerable Benign Detachment. Proc. Natl. Acad. Sci. USA 117 (27), 15497-15503. doi:10.1073/pnas.2006389117

Chen, Y., Cheng, W., Teng, L., Jin, M., Lu, B., Ren, L., et al. (2018). Graphene Oxide Hybrid Supramolecular Hydrogels with Self-Healable, Bioadhesive and StimuliResponsive Properties and Drug Delivery Application. Macromol. Mater. Eng. 303 (8), 1700660. doi:10.1002/mame.201700660

Cui, C., Fan, C., Wu, Y., Xiao, M., Wu, T., Zhang, D., et al. (2019). Water-Triggered Hyperbranched Polymer Universal Adhesives: From Strong Underwater Adhesion to Rapid Sealing Hemostasis. Adv. Mater. 31 (49), 1905761. doi:10.1002/adma.201905761

Cui, C., Wu, T., Gao, F., Fan, C., Xu, Z., Wang, H., et al. (2018). An Autolytic High Strength Instant Adhesive Hydrogel for Emergency Self-rescue. Adv. Funct. Mater. 28 (42), 1804925. doi:10.1002/adfm.201804925

Deng, J., Tang, Y., Zhang, Q., Wang, C., Liao, M., Ji, P., et al. (2019). A Bioinspired Medical Adhesive Derived from Skin Secretion of andrias Davidianus for Wound Healing. Adv. Funct. Mater. 29 (31), 1809110. doi:10.1002/ adfm.201809110

Deng, J., Yuk, H., Wu, J., Varela, C. E., Chen, X., Roche, E. T., et al. (2021). Electrical Bioadhesive Interface for Bioelectronics. Nat. Mater. 20 (2), 229-236. doi:10.1038/s41563-020-00814-2

Dowling, M. B., Kumar, R., Keibler, M. A., Hess, J. R., Bochicchio, G. V., and Raghavan, S. R. (2011). A Self-Assembling Hydrophobically Modified Chitosan Capable of Reversible Hemostatic Action. Biomaterials 32 (13), 3351-3357. doi:10.1016/j.biomaterials.2010.12.033

Du, X., Wu, L., Yan, H., Qu, L., Wang, L., Wang, X., et al. (2019). Multifunctional Hydrogel Patch with Toughness, Tissue Adhesiveness, and Antibacterial Activity for Sutureless Wound Closure. ACS Biomater. Sci. Eng. 5 (5), 2610-2620. doi:10.1021/acsbiomaterials.9b00130

Elvin, C. M., Vuocolo, T., Brownlee, A. G., Sando, L., Huson, M. G., Liyou, N. E., et al. (2010). A Highly Elastic Tissue Sealant Based on Photopolymerised Gelatin. Biomaterials $31 \quad$ (32), 8323-8331. doi:10.1016/ j.biomaterials.2010.07.032

Farrar, D. F. (2012). Bone Adhesives for Trauma Surgery: A Review of Challenges and Developments. Int. J. Adhes. Adhesives 33, 89-97. doi:10.1016/ j.ijadhadh.2011.11.009

Feng, Q., Wei, K., Lin, S., Xu, Z., Sun, Y., Shi, P., et al. (2016). Mechanically Resilient, Injectable, and Bioadhesive Supramolecular Gelatin Hydrogels Crosslinked by Weak Host-Guest Interactions Assist Cell Infiltration and In Situ Tissue Regeneration. Biomaterials 101, 217-228. doi:10.1016/ j.biomaterials.2016.05.043

Fonouni, H., Kashfi, A., Stahlheber, O., Konstantinidis, L., Kraus, T. W., Mehrabi, A., et al. (2017). Analysis of the Biliostatic Potential of Two Sealants in a Standardized Porcine Model of Liver Resection. Am. J. Surg. 214 (5), 945-955. doi:10.1016/j.amjsurg.2017.06.038

Gan, D., Xing, W., Jiang, L., Fang, J., Zhao, C., Ren, F., et al. (2019). Plant-inspired Adhesive and Tough Hydrogel Based on Ag-Lignin Nanoparticles-Triggered Dynamic Redox Catechol Chemistry. Nat. Commun. 10 (1), 1487. doi:10.1038/ s41467-019-09351-2

Ge, L., and Chen, S. (2020). Recent Advances in Tissue Adhesives for Clinical Medicine. Polymers 12 (4), 939. doi:10.3390/polym12040939

Giano, M. C., Ibrahim, Z., Medina, S. H., Sarhane, K. A., Christensen, J. M., Yamada, Y., et al. (2014). Injectable Bioadhesive Hydrogels with Innate Antibacterial Properties. Nat. Commun. 5, 4095. doi:10.1038/ncomms5095

Gong, C., Lu, C., Li, B., Shan, M., and Wu, G. (2017). Injectable DopamineModified Poly ( $\alpha, \beta$-Aspartic Acid) Nanocomposite Hydrogel as Bioadhesive Drug Delivery System. J. Biomed. Mater. Res. 105 (4), 1000-1008. doi:10.1002/ jbm.a.35931

Han, H.-K., Shin, H.-J., and Ha, D. H. (2012). Improved Oral Bioavailability of Alendronate via the Mucoadhesive Liposomal Delivery System. Eur. J. Pharm. Sci. 46 (5), 500-507. doi:10.1016/j.ejps.2012.04.002 
Han, L., Lu, X., Liu, K., Wang, K., Fang, L., Weng, L.-T., et al. (2017). Musselinspired Adhesive and Tough Hydrogel Based on Nanoclay Confined Dopamine Polymerization. ACS Nano 11 (3), 2561-2574. doi:10.1021/ acsnano.6b05318

Han, L., Wang, M., Li, P., Gan, D., Yan, L., Xu, J., et al. (2018). Mussel-inspired Tissue-Adhesive Hydrogel Based on the Polydopamine-Chondroitin Sulfate Complex for Growth-factor-free Cartilage Regeneration. ACS Appl. Mater. Inter. 10 (33), 28015-28026. doi:10.1021/acsami.8b05314

Han, L., Yan, L., Wang, K., Fang, L., Zhang, H., Tang, Y., et al. (2017). Tough, SelfHealable and Tissue-Adhesive Hydrogel with Tunable Multifunctionality. NPG Asia Mater. 9 (4), e372. doi:10.1038/am.2017.33

Harsha, K. S. S., and Vasudha, P. (2018). Cyanoacrylates: An Overview in its Application as a Tissue Adhesive. Der Pharma Chemica 10 (8), 42-46.

Hasani-Sadrabadi, M. M., Sarrion, P., Pouraghaei, S., Chau, Y., Ansari, S., Li, S., et al. (2020). An Engineered Cell-Laden Adhesive Hydrogel Promotes Craniofacial Bone Tissue Regeneration in Rats. Sci. Translational Med. 12 (534), eaay6853. doi:10.1126/scitranslmed.aay6853

Hong, S., Pirovich, D., Kilcoyne, A., Huang, C.-H., Lee, H., and Weissleder, R. (2016). Supramolecular Metallo-Bioadhesive for Minimally Invasive Use. $A d v$. Mater. 28 (39), 8675-8680. doi:10.1002/adma.201602606

Hong, Y., Zhou, F., Hua, Y., Zhang, X., Ni, C., Pan, D., et al. (2019). A Strongly Adhesive Hemostatic Hydrogel for the Repair of Arterial and Heart Bleeds. Nat. Commun. 10 (1), 2060. doi:10.1038/s41467-019-10004-7

Hu, J. K., Suh, H. W., Qureshi, M., Lewis, J. M., Yaqoob, S., Moscato, Z. M., et al. (2021). Nonsurgical Treatment of Skin Cancer with Local Delivery of Bioadhesive Nanoparticles. Proc. Natl. Acad. Sci. 118 (7), e2020575118. doi:10.1073/pnas.2020575118

Hwang, I., Kim, H. N., Seong, M., Lee, S.-H., Kang, M., Yi, H., et al. (2018). Multifunctional Smart Skin Adhesive Patches for Advanced Health Care. Adv. Healthc. Mater. 7 (15), 1800275. doi:10.1002/adhm.201800275

Jeon, E. Y., Hwang, B. H., Yang, Y. J., Kim, B. J., Choi, B.-H., Jung, G. Y., et al. (2015). Rapidly Light-Activated Surgical Protein Glue Inspired by Mussel Adhesion and Insect Structural Crosslinking. Biomaterials 67, 11-19. doi:10.1016/j.biomaterials.2015.07.014

Khademhosseini, A., and Langer, R. (2016). A Decade of Progress in Tissue Engineering. Nat. Protoc. 11 (10), 1775-1781. doi:10.1038/nprot.2016.123

Kim, H. J., Hwang, B. H., Lim, S., Choi, B.-H., Kang, S. H., and Cha, H. J. (2015a). Mussel Adhesion-Employed Water-Immiscible Fluid Bioadhesive for Urinary Fistula Sealing. Biomaterials 72, 104-111. doi:10.1016/j.biomaterials.2015.08.055

Kim, K., Ryu, J. H., Koh, M. Y., Yun, S. P., Kim, S., Park, J. P., et al. (2021). Coagulopathy-independent, Bioinspired Hemostatic Materials: A Full Research story from Preclinical Models to a Human Clinical Trial. Sci. Adv. 7 (13), eabc9992. doi:10.1126/sciadv.abc9992

Kim, K., Shin, M., Koh, M.-Y., Ryu, J. H., Lee, M. S., Hong, S., et al. (2015b). TAPE: A Medical Adhesive Inspired by a Ubiquitous Compound in Plants. Adv. Funct. Mater. 25 (16), 2402-2410. doi:10.1002/adfm.201500034

Kim, S.-H., Kim, K., Kim, B. S., An, Y.-H., Lee, U.-J., Lee, S.-H., et al. (2020). Fabrication of Polyphenol-Incorporated Anti-inflammatory Hydrogel via High-Affinity Enzymatic Crosslinking for Wet Tissue Adhesion. Biomaterials 242, 119905. doi:10.1016/j.biomaterials.2020.119905

Konieczynska, M. D., Villa-Camacho, J. C., Ghobril, C., Perez-Viloria, M., Tevis, K. M., Blessing, W. A., et al. (2016). On-demand Dissolution of a Dendritic Hydrogel-Based Dressing for Second-Degree Burn Wounds through ThiolThioester Exchange Reaction. Angew. Chem. Int. Ed. 55 (34), 9984-9987. doi:10.1002/anie.201604827

Krishnadoss, V., Melillo, A., Kanjilal, B., Hannah, T., Ellis, E., Kapetanakis, A., et al. (2019). Bioionic Liquid Conjugation as Universal Approach to Engineer Hemostatic Bioadhesives. ACS Appl. Mater. Inter. 11 (42), 38373-38384. doi:10.1021/acsami.9b08757

Lang, N., Pereira, M. J., Lee, Y., Friehs, I., Vasilyev, N. V., Feins, E. N., et al. (2014). A Blood-Resistant Surgical Glue for Minimally Invasive Repair of Vessels and Heart Defects. Sci. Translational Med. 6 (218), 218ra6. doi:10.1126/ scitranslmed.3006557

Li, J., and Mooney, D. J. (2016). Designing Hydrogels for Controlled Drug Delivery. Nat. Rev. Mater. 1 (12), 1-17. doi:10.1038/natrevmats.2016.71

Li, S., Zhou, J., Huang, Y., Roy, J., Zhou, N., Yum, K., et al. (2020). Injectable Click Chemistry-Based Bioadhesives for Accelerated Wound Closure. Acta Biomater. 110, 95-104. doi:10.1016/j.actbio.2020.04.004
Liang, Y., Zhao, X., Hu, T., Chen, B., Yin, Z., Ma, P. X., et al. (2019). Adhesive Hemostatic Conducting Injectable Composite Hydrogels with Sustained Drug Release and Photothermal Antibacterial Activity to Promote Full-Thickness Skin Regeneration during Wound Healing. Small 15 (12), 1900046. doi:10.1002/smll.201900046

Lih, E., Lee, J. S., Park, K. M., and Park, K. D. (2012). Rapidly Curable ChitosanPEG Hydrogels as Tissue Adhesives for Hemostasis and Wound Healing. Acta Biomater. 8 (9), 3261-3269. doi:10.1016/j.actbio.2012.05.001

Lin, X., Liu, Y., Bai, A., Cai, H., Bai, Y., Jiang, W., et al. (2019). A Viscoelastic Adhesive Epicardial Patch for Treating Myocardial Infarction. Nat. Biomed. Eng. 3 (8), 632-643. doi:10.1038/s41551-019-0380-9

Liu, B., Wang, Y., Miao, Y., Zhang, X., Fan, Z., Singh, G., et al. (2018). Hydrogen Bonds Autonomously Powered Gelatin Methacrylate Hydrogels with Superelasticity, Self-Heal and Underwater Self-Adhesion for Sutureless Skin and Stomach Surgery and E-Skin. Biomaterials 171, 83-96. doi:10.1016/ j.biomaterials.2018.04.023

Liu, C., Liu, X., Liu, C., Wang, N., Chen, H., Yao, W., et al. (2019). A Highly Efficient, In Situ Wet-Adhesive Dextran Derivative Sponge for Rapid Hemostasis. Biomaterials 205, 23-37. doi:10.1016/ j.biomaterials.2019.03.016

Lu, M., Liu, Y., Huang, Y.-C., Huang, C.-J., and Tsai, W.-B. (2018). Fabrication of Photo-Crosslinkable Glycol Chitosan Hydrogel as a Tissue Adhesive. Carbohydr. Polym. 181, 668-674. doi:10.1016/j.carbpol.2017.11.097

Lu, X., Shi, S., Li, H., Gerhard, E., Lu, Z., Tan, X., et al. (2020). Magnesium OxideCrosslinked Low-Swelling Citrate-Based Mussel-Inspired Tissue Adhesives. Biomaterials 232, 119719. doi:10.1016/j.biomaterials.2019.119719

Macnab, A., Pagano, R., Kwon, B., Dumont, G., and Shadgan, B. (2018). “In Vivo Near Infrared (NIRS) Sensor Attachment Using Fibrin Bioadhesive", in Proceedings Volume 10501, Optical Diagnostics and Sensing XVIII: Toward Point-of-Care Diagnostics (San Francisco, California, United States: SPIE BiOS), 1-8.

Margules, A. C., and Rovner, E. S. (2019). The Use of Tissue Flaps in the Management of Urinary Tract Fistulas. Curr. Urol. Rep. 20 (6), 32. doi:10.1007/s11934-019-0892-6

Mehdizadeh, M., Weng, H., Gyawali, D., Tang, L., and Yang, J. (2012). Injectable Citrate-Based Mussel-Inspired Tissue Bioadhesives with High Wet Strength for Sutureless Wound Closure. Biomaterials 33 (32), 7972-7983. doi:10.1016/ j.biomaterials.2012.07.055

Mehdizadeh, M., and Yang, J. (2013). Design Strategies and Applications of Tissue Bioadhesives. Macromol. Biosci. 13 (3), 271-288. doi:10.1002/mabi.201200332

Mueller, M. R., and Marzluf, B. A. (2014). The Anticipation and Management of Air Leaks and Residual Spaces post Lung Resection. J. Thorac. Dis. 6 (3), 271-284. doi:10.3978/j.issn.2072-1439.2013.11.29

Nie, W., Yuan, X., Zhao, J., Zhou, Y., and Bao, H. (2013). Rapidly In Situ Forming Chitosan/ع-Polylysine Hydrogels for Adhesive Sealants and Hemostatic Materials. Carbohydr. Polym. 96 (1), 342-348. doi:10.1016/ j.carbpol.2013.04.008

Patel, R. G., Purwada, A., Cerchietti, L., Inghirami, G., Melnick, A., Gaharwar, A. K., et al. (2014). Microscale Bioadhesive Hydrogel Arrays for Cell Engineering Applications. Cel. Mol. Bioeng. 7 (3), 394-408. doi:10.1007/s12195-014-0353-8

Pathak, K., and Malviya, R. (2020). Introduction, Theories and Mechanisms of Bioadhesion, Bioadhesives in Drug Delivery, 1-27. doi:10.1002/ 9781119640240.ch1

Pausch, T. M., Mitzscherling, C., Abbasi, S., Cui, J., Liu, X., Aubert, O., et al. (2020). SmartPAN: A Novel Polysaccharide-Microsphere-Based Surgical Indicator of Pancreatic Leakage. J. Biomater. Appl. 35 (1), 123-134. doi:10.1177/ 0885328220913057

Qu, J., Zhao, X., Liang, Y., Zhang, T., Ma, P. X., and Guo, B. (2018). Antibacterial Adhesive Injectable Hydrogels with Rapid Self-Healing, Extensibility and Compressibility as Wound Dressing for Joints Skin Wound Healing. Biomaterials 183, 185-199. doi:10.1016/j.biomaterials.2018.08.044

Reddy, P. C., Chaitanya, KS., and Madhusudan Rao, Y. (2011). A Review on Bioadhesive Buccal Drug Delivery Systems: Current Status of Formulation and Evaluation Methods. DARU J. Pharm. Sci. 19 (6), 385.

Ryu, J. H., Lee, Y., Kong, W. H., Kim, T. G., Park, T. G., and Lee, H. (2011). Catechol-functionalized Chitosan/Pluronic Hydrogels for Tissue Adhesives and Hemostatic Materials. Biomacromolecules 12 (7), 2653-2659. doi:10.1021/bm200464x 
Schiavone, G., and Lacour, SP. (2019). Conformable Bioelectronic Interfaces: Mapping the Road Ahead. Sci. Translational Med. 11, eaaw5858. doi:10.1126/scitranslmed.aaw5858

Shin, J., Lee, J. S., Lee, C., Park, H.-J., Yang, K., Jin, Y., et al. (2015). Tissue Adhesive Catechol-Modified Hyaluronic Acid Hydrogel for Effective, Minimally Invasive Cell Therapy. Adv. Funct. Mater. 25 (25), 3814-3824. doi:10.1002/ adfm.201500006

Shin, M., Kim, K., Shim, W., Yang, J. W., and Lee, H. (2016). Tannic Acid as a Degradable Mucoadhesive Compound. ACS Biomater. Sci. Eng. 2 (4), 687-696. doi:10.1021/acsbiomaterials.6b00051

Shin, M., Park, S.-G., Oh, B.-C., Kim, K., Jo, S., Lee, M. S., et al. (2016). Complete Prevention of Blood Loss with Self-Sealing Haemostatic needles. Nat. Mater 16, 147-152. doi:10.1038/nmat4758

Shin, M., Ryu, J. H., Park, J. P., Kim, K., Yang, J. W., and Lee, H. (2015). DNA/ Tannic Acid Hybrid Gel Exhibiting Biodegradability, Extensibility, Tissue Adhesiveness, and Hemostatic Ability. Adv. Funct. Mater. 25 (8), 1270-1278. doi:10.1002/adfm.201403992

Shirzaei Sani, E., Kheirkhah, A., Rana, D., Sun, Z., Foulsham, W., Sheikhi, A., et al. (2019). Sutureless Repair of Corneal Injuries Using Naturally Derived Bioadhesive Hydrogels. Sci. Adv. 5 (3), eaav1281. doi:10.1126/sciadv.aav1281

Slieker, J. C., Daams, F., Mulder, I. M., Jeekel, J., and Lange, J. F. (2013). Systematic Review of the Technique of Colorectal Anastomosis. JAMA Surg. 148 (2), 190-201. doi:10.1001/2013.jamasurg.33

Spotnitz, W. D., and Burks, S. (2012). Hemostats, Sealants, and Adhesives III: A New Update as Well as Cost and Regulatory Considerations for Components of the Surgical Toolbox. Transfusion 52 (10), 2243-2255. doi:10.1111/j.15372995.2012.03707.x

Sun, F., Bu, Y., Chen, Y., Yang, F., Yu, J., and Wu, D. (2020). An Injectable and Instant Self-Healing Medical Adhesive for Wound Sealing. ACS Appl. Mater. Inter. 12 (8), 9132-9140. doi:10.1021/acsami.0c01022

Taboada, G. M., Yang, K., Pereira, M. J. N., Liu, S. S., Hu, Y., Karp, J. M., et al. (2020). Overcoming the Translational Barriers of Tissue Adhesives. Nat. Rev. Mater. 5 (4), 310-329. doi:10.1038/s41578-019-0171-7

Tan, H., Jin, D., Qu, X., Liu, H., Chen, X., Yin, M., et al. (2019). A PEG-Lysozyme Hydrogel Harvests Multiple Functions as a Fit-To-Shape Tissue Sealant for Internal-Use of Body. Biomaterials 192, 392-404. doi:10.1016/ j.biomaterials.2018.10.047

Villa-Camacho, J. C., Ghobril, C., Anez-Bustillos, L., Grinstaff, M. W., Rodríguez, E. K., and Nazarian, A. (2015). The Efficacy of a Lysine-Based Dendritic Hydrogel Does Not Differ from Those of Commercially Available Tissue Sealants and Adhesives: An Ex Vivo Study. BMC Musculoskelet. Disord. 16 (116), 1-6. doi:10.1186/s12891-015-0573-7

Walker, B. W., Lara, R. P., Yu, C. H., Sani, E. S., Kimball, W., Joyce, S., et al. (2019). Engineering a Naturally-Derived Adhesive and Conductive Cardiopatch. Biomaterials 207, 89-101. doi:10.1016/j.biomaterials.2019.03.015

Wijetunge, S. S., Wen, J., Yeh, C.-K., and Sun, Y. (2018). Lectin-conjugated Liposomes as Biocompatible, Bioadhesive Drug Carriers for the Management of Oral Ulcerative Lesions. ACS Appl. Bio Mater. 1 (5), 1487-1495. doi:10.1021/acsabm.8b00425

Xie, D., Guo, J., Mehdizadeh, M. R., Tran, R. T., Chen, R., Sun, D., et al. (2015). Development of Injectable Citrate-Based Bioadhesive Bone Implants. J. Mater. Chem. $B 3$ (3), 387-398. doi:10.1039/c4tb01498g

Yan, S., Wang, W., Li, X., Ren, J., Yun, W., Zhang, K., et al. (2018). Preparation of Mussel-Inspired Injectable Hydrogels Based on Dual-Functionalized Alginate with Improved Adhesive, Self-Healing, and Mechanical Properties. J. Mater. Chem. B 6 (40), 6377-6390. doi:10.1039/c8tb01928b

Yanagihara, T., Maki, N., Wijesinghe, A. I., Sato, S., Saeki, Y., Kitazawa, S., et al. (2021). Efficacy of Alaska pollock Gelatin Sealant for Pulmonary Air Leakage in
Porcine Models. Ann. Thorac. Surg. S0003-4975 (21), 00978-4. doi:10.1016/ j.athoracsur.2021.05.023

Yang, S. Y., O'Cearbhaill, E. D., Sisk, G. C., Park, K. M., Cho, W. K., Villiger, M., et al. (2013). A Bio-Inspired Swellable Microneedle Adhesive for Mechanical Interlocking with Tissue. Nat. Commun. 4, 1702. doi:10.1038/ncomms2715

Yang, Y., Zhao, X., Yu, J., Chen, X., Wang, R., Zhang, M., et al. (2021). Bioactive Skin-Mimicking Hydrogel Band-Aids for Diabetic Wound Healing and Infectious Skin Incision Treatment. Bioactive Mater. 6 (11), 3962-3975. doi:10.1016/j.bioactmat.2021.04.007

Yuk, H., Lu, B., and Zhao, X. (2019). Hydrogel Bioelectronics. Chem. Soc. Rev. 48 (6), 1642-1667. doi:10.1039/c8cs00595h

Yuk, H., Varela, C. E., Nabzdyk, C. S., Mao, X., Padera, R. F., Roche, E. T., et al. (2019). Dry Double-Sided Tape for Adhesion of Wet Tissues and Devices. Nature 575 (7781), 169-174. doi:10.1038/s41586-019-1710-5

Zhang, C., Tang, J., Liu, D., Li, X., Cheng, L., and Tang, X. (2016). Design and Evaluation of an Innovative Floating and Bioadhesive Multiparticulate Drug Delivery System Based on Hollow Structure. Int. J. Pharmaceutics 503 (1-2), 41-55. doi:10.1016/j.ijpharm.2016.02.045

Zhang, L., Zuo, X., Li, S., Sun, M., Xie, H., Zhang, K., et al. (2019). Synergistic Therapy of Magnetism-Responsive Hydrogel for Soft Tissue Injuries. Bioactive Mater. 4, 160-166. doi:10.1016/j.bioactmat.2019.03.002

Zhang, Y., Yu, Y., Li, G., Meng, H., Zhang, X., Dong, L., et al. (2020). A Bioadhesive Nanoplatform Enhances the Permeation of Drugs Used to Treat Diabetic Macular Edema. ACS Appl. Bio Mater. 3 (4), 2314-2324. doi:10.1021/ acsabm.0c00080

Zhao, X., Liang, Y., Huang, Y., He, J., Han, Y., and Guo, B. (2020). Physical Double-Network Hydrogel Adhesives with Rapid Shape Adaptability, Fast Self-Healing, Antioxidant and NIR/pH Stimulus-Responsiveness for Multidrug-Resistant Bacterial Infection and Removable Wound Dressing. Adv. Funct. Mater. 30 (17), 1910748. doi:10.1002/ adfm. 201910748

Zhao, X., Wu, H., Guo, B., Dong, R., Qiu, Y., and Ma, P. X. (2017). Antibacterial Anti-oxidant Electroactive Injectable Hydrogel as Self-Healing Wound Dressing with Hemostasis and Adhesiveness for Cutaneous Wound Healing. Biomaterials 122, 34-47. doi:10.1016/j.biomaterials.2017.01.011

Zhu, W., Chuah, Y. J., and Wang, D.-A. (2018). Bioadhesives for Internal Medical Applications: A Review. Acta Biomater. 74, 1-16. doi:10.1016/ j.actbio.2018.04.034

Zhu, W., Peck, Y., Iqbal, J., and Wang, D.-A. (2017). A Novel DOPA-Albumin Based Tissue Adhesive for Internal Medical Applications. Biomaterials 147, 99-115. doi:10.1016/j.biomaterials.2017.09.016

Conflict of Interest: The authors declare that the research was conducted in the absence of any commercial or financial relationships that could be construed as a potential conflict of interest.

Publisher's Note: All claims expressed in this article are solely those of the authors and do not necessarily represent those of their affiliated organizations, or those of the publisher, the editors and the reviewers. Any product that may be evaluated in this article, or claim that may be made by its manufacturer, is not guaranteed or endorsed by the publisher.

Copyright (๑) 2021 Duan, Bian and Bu. This is an open-access article distributed under the terms of the Creative Commons Attribution License (CC BY). The use, distribution or reproduction in other forums is permitted, provided the original author(s) and the copyright owner(s) are credited and that the original publication in this journal is cited, in accordance with accepted academic practice. No use, distribution or reproduction is permitted which does not comply with these terms. 